\title{
Mechanisms of amphibian macrophage development: characterization of the Xenopus laevis colony-stimulating factor-1 receptor
}

\author{
LEON GRAYFER, EVA-STINA EDHOLM and JACQUES ROBERT** \\ Department of Microbiology and Immunology, University of Rochester Medical Center, Rochester, USA
}

\begin{abstract}
Macrophage-lineage cells are indispensable to vertebrate homeostasis and immunity. In turn, macrophage development is largely regulated through colony-stimulating factor-1 (CSF1) binding to its cognate receptor (CSF1R). To study amphibian monopoiesis, we identified and characterized the $X$. laevis CSF1R cDNA transcript. Quantitative analysis revealed that $C S F 1 R$ tissue gene expression increased with $X$. laevis development, with greatest transcript levels detected in the adult lung, spleen and liver tissues. Notably, considerable levels of CSF1R mRNA were also detected in the regressing tails of metamorphosing animals, suggesting macrophage involvement in this process, and in the adult bone marrow; corroborating the roles for this organ in Xenopus monopoiesis. Following animal infections with the ranavirus Frog Virus 3 (FV3), both tadpole and adult $X$. laevis exhibited increased kidney CSF1R gene expression. Conversely, while FV3-infected tadpoles increased their spleen and liver CSF1R mRNA levels, the FV3-challenged adults did not. Notably, FV3 induced elevated bone marrow CSF1R expression, and while stimulation of tadpoles with heat-killed $E$. coli had no transcriptional effects, bacterial stimulation of adult frogs resulted in significantly increased spleen, liver and bone marrow CSF1R expression. We produced the $X$. laevis CSF1R in recombinant form ( $\mathrm{r} X \mathrm{CSF} 1 \mathrm{R})$ and determined, via in vitro cross-linking studies, that two molecules of $r$ XICSF1R bound the dimeric $r$ XICSF1. Finally, administration of $r$ XICSF1R abrogated the $\mathrm{r} X I C S F 1$-induced tadpole macrophage recruitment and differentiation as well as bacterial and FV3-elicited peritoneal leukocyte accumulation. This work marks a step towards garnering greater understanding of the unique mechanisms governing amphibian macrophage biology.
\end{abstract}

KEY WORDS: Xenopus, monopoiesis, CSF1, macrophage development, ranavirus

\section{Introduction}

Macrophage-lineage cells are indispensable to homeostasis and host defenses of all vertebrate species. Monopoiesis, or the development and differentiation of macrophage lineage cells is chiefly mediated by the colony stimulating factor-1 (CSF1; macrophage colony-stimulating factor, MCSF) cytokine and growth factor (Garceau et al., 2010; Hanington et al., 2007; Pixley and Stanley, 2004; Wang etal., 2008). CSF1 functions as a homo-dimer, ligating the high-affinity tyrosine kinase CSF1 receptor (CSF1R) (Dai et al., 2002), the cell surface expression of which is restricted predominantly to mononuclear phagocytes and their derivative cell populations (Guilbert and Stanley, 1980; Lichanska et al., 1999).

In mammals, the expression levels of the CSF1R increase progressively with macrophage development, from lower levels by myeloid precursors to greater levels by monocytes and further elevated levels by terminally differentiated macrophages (Stanley et al., 1997). Furthermore, the ligation of CSF1R by CSF1 is critical not only to macrophage proliferation, differentiation and survival, but also for effective antimicrobial and anti-tumor host responses orchestrated by these cells (Bober et al., 1995; Karbassi et al., 1987; Munn and Cheung, 1995; Sweet and Hume, 2003). Thus, CSF1R gene expression serves as a reliable marker in the study of monopoiesis during animal development and host immune responses.

Despite the fact that more ancestral vertebrate species possess the CSF1/CSF1R monopoietic systems, the evolutionary origins of these pathways remain poorly understood. CSF 1 is present in birds (Garceau et al., 2010), amphibians (Grayfer and Robert, 2013),

Abbreviations used in this paper: CSF-1, colony-stimulating factor-1; FV3, frog virus 3.

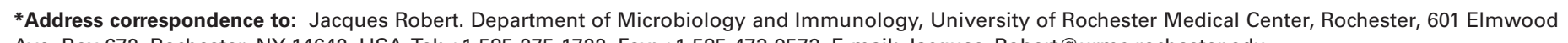
Ave, Box 672, Rochester, NY 14642, USA. Tel: +1-585-275-1722. Fax: +1-585-473-9573. E-mail: Jacques_Robert@urmc.rochester.edu 

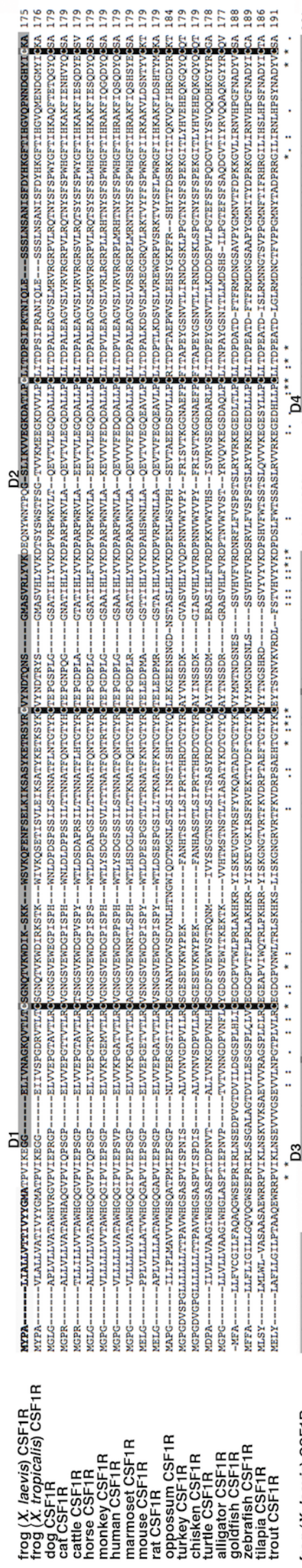
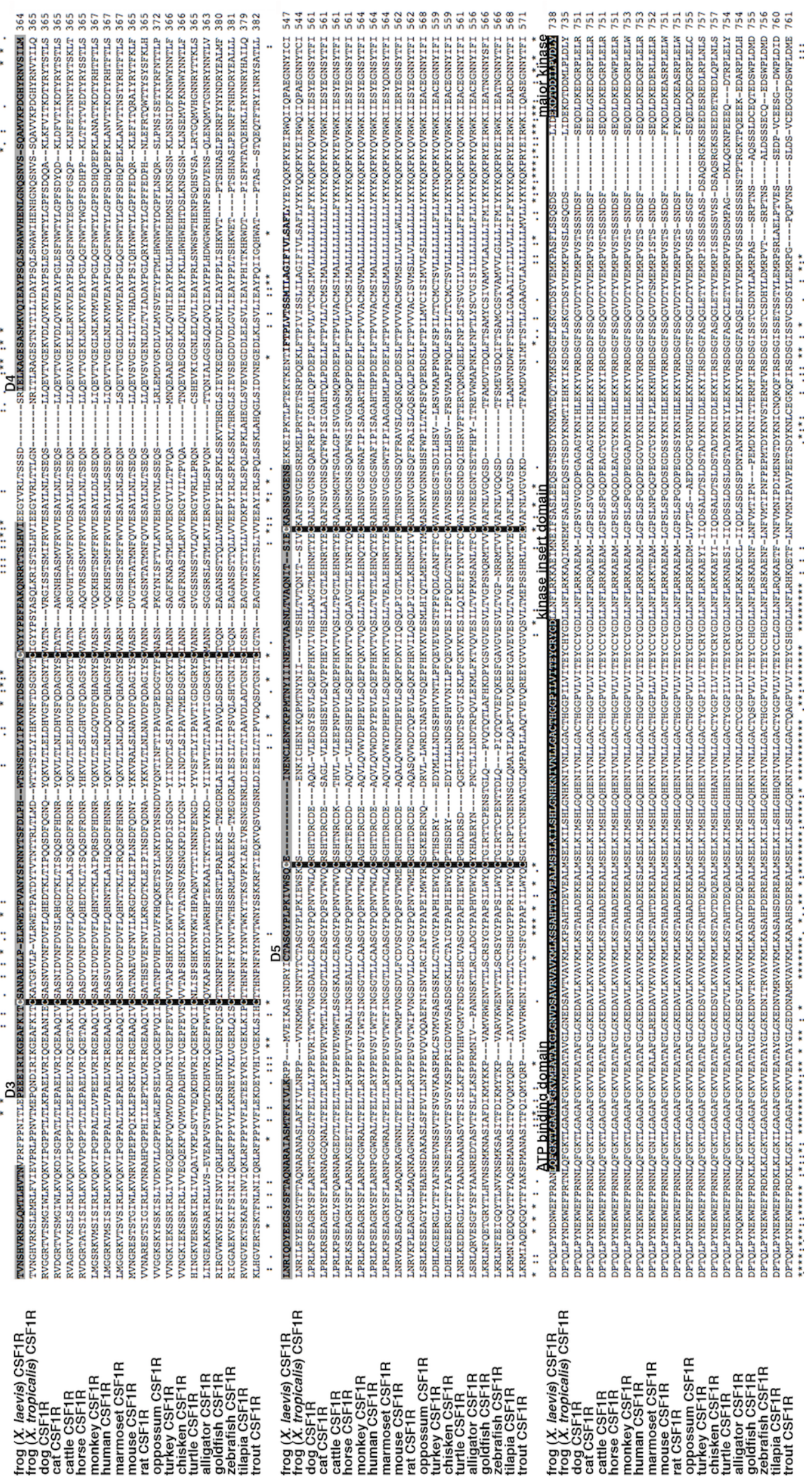

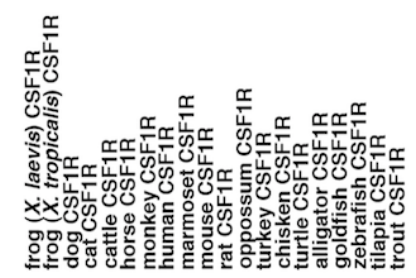




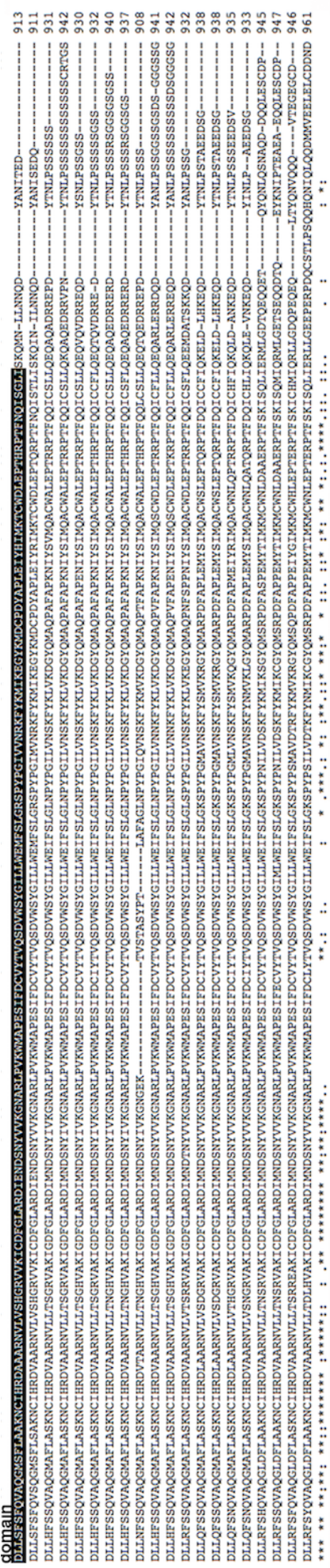

Fig. 1. Amino acid alignment of $X$. laevis CSF1R with other vertebrate CSF1R protein sequences. Protein alignments were performed using ClustalW2 server. Fully conserved residues are indicated by an asterisk (*), partially conserved and semiconserved substitutions are represented by ":" and :." respectively. The X. laevis CSF1R signal peptide is in bold, the immunoglobulinlike domains are indicated as D1-D5, the evolutionarily conserved structural cysteines are in white text within black boxes and the transmembrane domain is also in bold face. As indicated overhead; the $\mathrm{X}$. laevis CSF1R ATP binding and tryrosine kinase major catalystic domains are in white text within black boxes while the kinase insert domain is indicated by an overhead line.
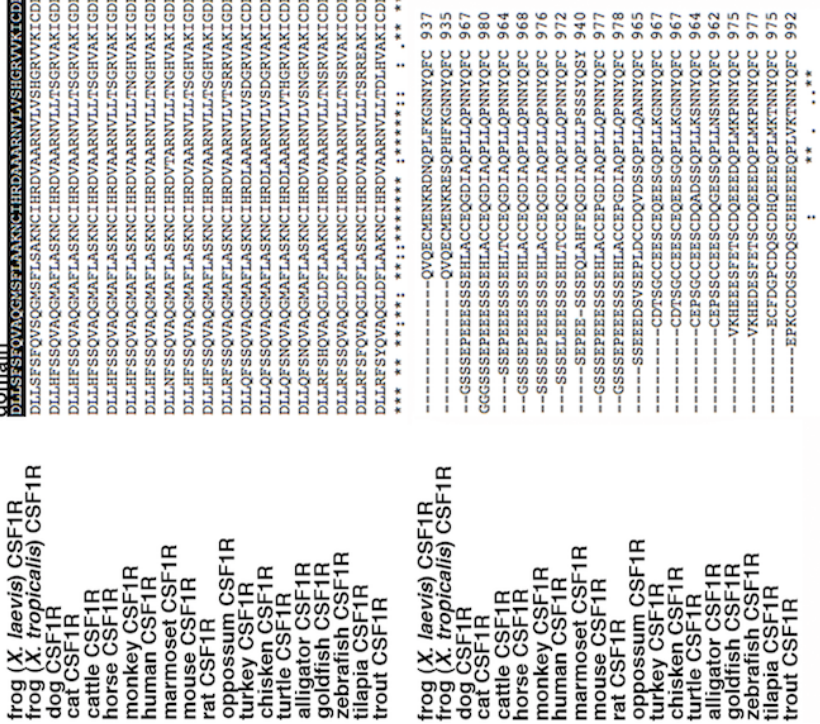

and bony fish (Hanington et al., 2007); and CSF1Rs have been identified, in birds (Garceau et al., 2010) and teleosts (Barreda et al., 2005; Honda et al., 2005; How et al., 1996; Parichy et al., 2000; Pettersen et al., 2008). However, it appears that the bony fish CSF1 ligand-receptor axis is distinct to that of mammals (Hanington et al., 2007; Wang et al., 2008; Wang et al., 2014). Indeed, fish species possess multiple distinct gene copies of both the CSF1 ligand and receptor, which contrasts to single copies seen across higher vertebrates. Owing to the key position occupied by amphibians in vertebrate evolution, it would be interesting to determine whether the Xenopus CSF1 ligand-receptor system is more reminiscent of those seen in fish, mammals or alternatively a hybrid intermediate. Moreover, amphibian macrophage development remains to be fully characterized. Notably, monopoiesis of most vertebrate species occurs within designated hematopoietic tissues/organs such as the bone marrow of birds and mammals (Garceau et al., 2010; Tushinski et al., 1982) and the teleost head kidney (Belosevic et al., 2006; Neumann et al., 2000). By contrast, although the Xenopus liver periphery clearly functions as primary site of hematopoiesis (Hadji-Azimi et al., 1987; Hadji-Azimi et al., 1990; Lane and Sheets, 2002), our recent findings indicate that rather than the subcapsular liver, the bone marrow functions as the primary site of $X$. laevis macrophage development and contains CSF1 responsive macrophage precursors (Grayfer and Robert, 2013).

Infections of amphibians by ranaviruses (family Iridoviridae) and the resulting population die-offs are now believed to be a significant contributing factor to amphibian declines (Chinchar, 2002; Chinchar et al., 2009; Williams et al., 2005). A growing body of literature indicates that amphibian macrophage-lineage cells are critical players in both anti-ranaviral immunity and the ranavirus infection strategies (reviewed in Grayfer et al., 2012). Thus, greater insight into amphibian macrophage development may contribute to bridging the gap in our understanding of the evolution of vertebrate monopoiesis and to studying ranaviruses and developing preventative measures against these emerging pathogens.

Accordingly, to begin to delineate the roles of CSF1R in amphibian macrophage development and anti-RV immunity, we identified the $X$. laevis CSF1R, characterized the expression of this gene in developing, bacterially and virally challenged $X$. laevisand assessed the biological efficacies of a recombinant form of the $X$. laevis CSF1R protein. This manuscript marks the first characterization of an amphibian colony-stimulating factor-1 receptor.

\section{Results}

\section{Identification and amino acid alignment analysis of the $X$. laevis CSF1R}

To investigate amphibian macrophage development, we identified the full cDNA transcript encoding the $X$. laevis principal macrophage growth factor receptor, the colony-stimulating factor-1 receptor (CSF1R) by means of conventional and RACE PCR. The extracellular portion of the putative $X$. laevis CSF1R exhibits low amino acid sequence identity with the CSF1R molecules of other vertebrate species. However, all of these molecules have in common conserved and structurally important cysteine residues and the presence of five putative immunoglobulin-like domains (D1-D5; Fig. 1). Akin to the other vertebrate CSF1Rs, the putative $X$. laevis receptor possesses a disrupted intracellular domain composed of an ATP binding motif, a kinase insert domain as well as a major 
tyrosine kinase catalytic domain (Fig. 1). Notably, in contrast to the poor amino acid sequence conservation across the extracellular portions of the vertebrate CSF1Rs (including that of $X$. laevis), the intracellular components of these respective proteins exhibit many stretches of evolutionarily conserved residues, particularly throughout the tyrosine kinase catalytic domains (Fig. 1).

\section{Phylogenetic analysis of vertebrate CSF1R proteins}

Phylogenetic analysis of the putative vertebrate CSF1 R protein sequences indicated a clear evolutionary relationship, wherein the fish CSF1Rs formed a separate clade, ancestral to the amphibian CSF1Rs, which in turn branched independently and ancestral to other vertebrate CSF1Rs (Fig. 2). The orthology of the Xenopus sequences is supported by high boostrap values (Fig. 2). Notably, the avian and reptilian CSF1R molecules branched closer together, in a separate clade from the marsupial and mammalian CSF1R proteins (Fig. 2). The zebrafish KitR, which is structurally related to CSF1R, was used as an out-group to root the tree (Fig. 2).

\section{Quantitative analysis of CSF1R gene expression in tissues of} tadpoles, metamorphic and adult $X$. laevis

Since CSF1R is primarily expressed by macrophage-lineage

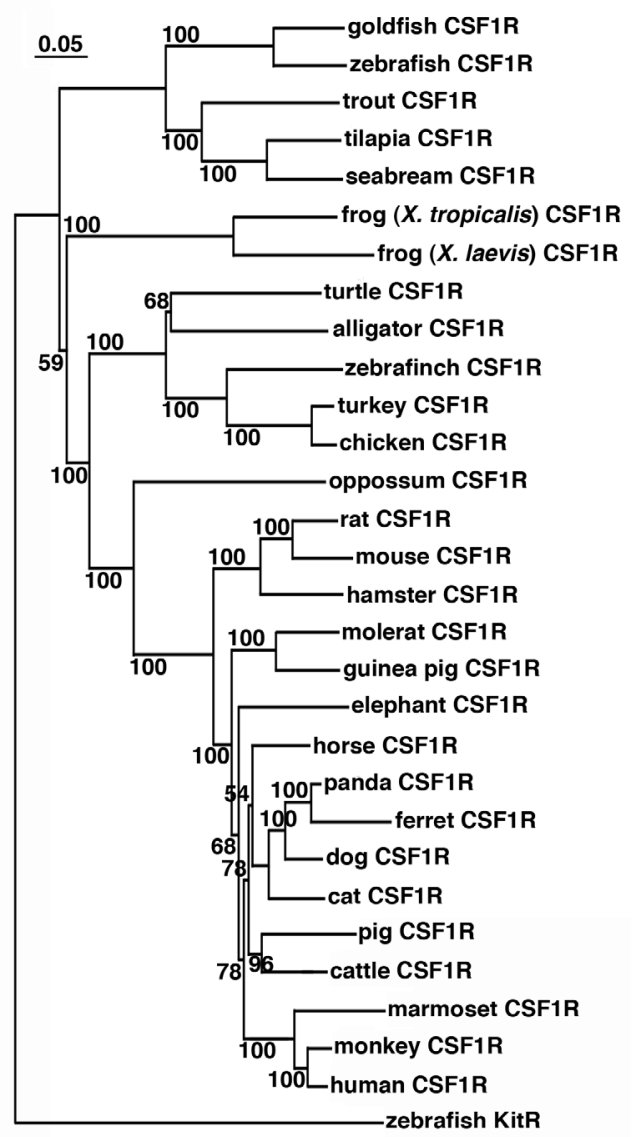

Fig. 2. Phylogenetic analysis of teleost, amphibian, reptile, avian and mammalian colony-stimulating factor-1 receptor (CSF1R) molecules. The phylogenetic tree was constructed from multiple deduced amino acid sequence alignments using the neighbor joining method and bootstrapped 10,000 times (denoted as \%). The zebrafish KitR was used as outgroup to root the tree.

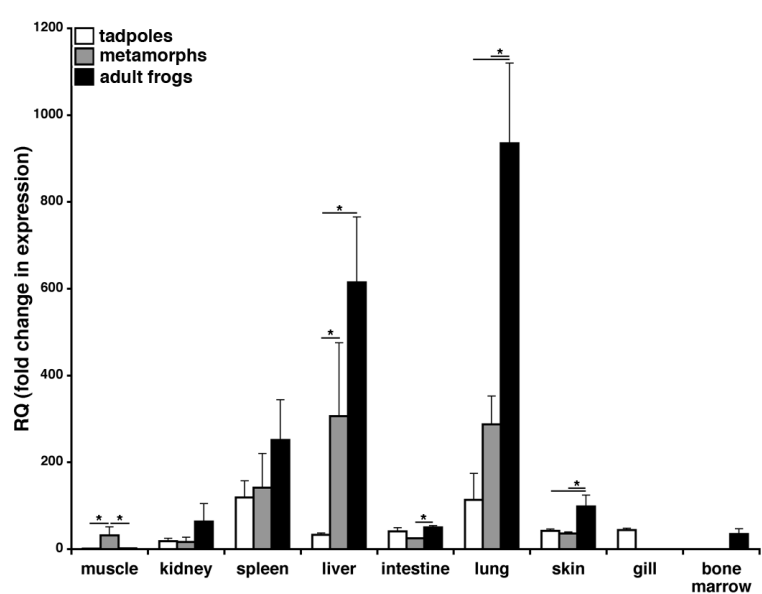

Fig. 3. Quantitative colony-stimulating factor-1 receptor (CSF1R) tissue gene expression analysis of tadpoles (Stg. 54), metamorphic (Stg. 64) and adult (2 years-old) frogs. Tissues from three individuals ( $N$ =3) were used for all expression studies, the expression was performed via the delta^delta CT method using X. laevis CSF1R-specific primers. The expression examined relative to the GAPDH endogenous control and normalized against the tadpole muscle tissue expression. Results are means $\pm S E M, N=4$ and the $\left(^{*}\right)$ above lines denotes significant difference between tissues indicated by the lines, $P<0.05$

cells, we next wanted to examine the quantitative gene expression of the $X$. laevis CSF1R in tadpoles (Stg. 54; (Thors et al., 1982a; Thors et al., 1982b)), metamorphs (Stg. 64) and adults (2 years old) and hence delineate the distribution of macrophage populations during development (Fig. 3). CSF1R gene expression in tadpole and adult muscle was low, whereas CSF1R mRNA levels were significantly greater in regressing tail-muscle tissues of metamorphosing animals (Fig. 3), consistent with the accumulation of active macrophages involved in tail reabsorption (Nishikawa et al., 1998). The spleen, liver and lung CSF1R gene expression increased with development, where the metamorph and adult liver and lung CSF1R transcript levels were significantly greater than those seen in the respective tadpole tissues (Fig. 3). Interestingly, the lung CSF1R mRNA levels were also significantly greater than those see in tadpoles and metamorphs (Fig. 3). Finally, marginal but detectable levels of CSF1R transcripts were detected in the adult bone marrow (Fig. 3).

Quantitative analysis of CSF1R gene expression in tissue of $X$. laevis tadpoles and adult frogs immunologically challenged with FV3 and heat-killed E. coli

To infer on macrophage distribution upon immunological challenge, we examined the expression of CSF1R following infection with the ranavirus Frog Virus 3 (FV3; Iridoviridae) or after injections with heat-killed E. coli (Fig. 4). In tadpoles, the kidney, which is the central site of FV3 replication, exhibited a modest but significant increase in the CSF1R gene expression at 3 days post FV3 infection (dpi), followed by a decrease at 6 dpi (Fig. 4A). In contrast, a substantial increase of CSFR1 gene expression was observed in tadpole spleens (the primary amphibian immune tissue) at 6 (but not 3) dpi (Fig. 4A). The hematopoietic tadpole liver exhibited significant transcriptional increases in CSF1R at both 3 and $6 \mathrm{dpi}$ (Fig. 4A). Interestingly, challenge of tadpoles with heat-killed $E$. 

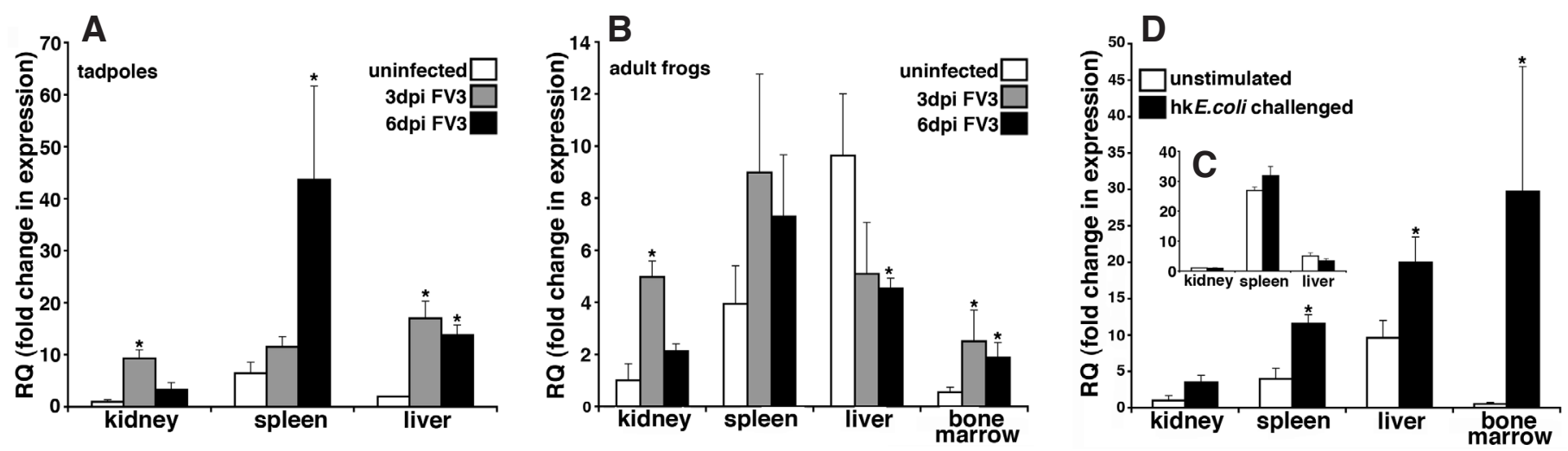

Fig. 4. Quantitative analysis of colony-stimulating factor-1 receptor (CSF1R) tissue gene expression in Frog Virus 3 (FV3) and heat-killed E. coli challenged tadpoles and adult $\boldsymbol{X}$. laevis. Tadpoles (Stg. 54) and adult frogs (2 years-old) were infected by ip injections with $1 \times 10^{4}$ and $5 \times 10^{6}$ PFU

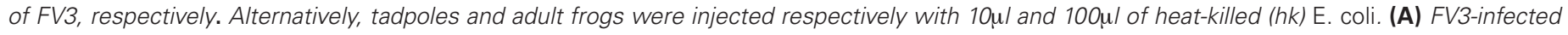
tadpole CSF1R gene expression. (B) FV3-infected tadult frog CSF1R gene expression. (C) Heat-killed E. coli-stimulated tadpole CSF1R gene expression. (D) Heat-killed E. coli-stimulated adult frog CSF1R gene expression. All gene expression analysis was performed via the delta^delta CT method using $X$. laevis CSF1R-specific primers, the expression examined relative to the GAPDH endogenous control and normalized against respective uninfected kidney expression. Results are means $\pm S E M, N=4$ and the $\left(^{*}\right)$ above lines denotes significant difference between tissues indicated by the lines, $P<0.05$.

coli had no bearing on CSF1R gene expression (Fig. 4C).

As in tadpoles, FV3 infection of adult frogs resulted in increased kidney CSF1Rgene expression at $3 \mathrm{dpi}$ and a subsequent decrease at 6 dpi (Fig. 4B). In contrast to the increased CSF1R gene expression in tadpole spleens following FV3 infection, no significant increase of CSF1R gene expression was observed in adult spleens following ranaviral challenge (Fig. 4B). Furthermore, the adult liver CSF1R gene expression decreased following FV3 infection, significantly so at 6 dpi (Fig. 4B). The bone marrow CSF1R gene expression was significantly increased at both 3 and 6 dpi (Fig. 4B), supporting our previous findings that the amphibian bone marrow may serve as a site of monopoiesis (Grayfer and Robert, 2013),

Intriguingly and again in contrast to the tadpole expression patterns; six days following heat-killed E. coli stimulation of adult frogs, these animals possessed significantly elevated spleen, liver and bone marrow CSF1R gene expression, where the magnitude of the bone marrow upregulation of this gene far exceeded any other CSF1R transcriptional changes reported here (Fig. 4C).

\section{In vitro rXICSF1 and rXICSF1R binding studies}

To confirm that the Xenopus CSF1R is the cognate receptor for the monopoietic CSF1 ligand, we produced recombinant $r$ XICSF1R and $\mathrm{r} X I \mathrm{CS} F 1$ molecules using an insect expression system, and assessed ligand-receptor binding in vitro using the disuccinimidyl suberate (DSS, $2.5 \mathrm{mM}$ final concentration) crosslinker to stabilize protein interactions and western blot analysis against the $\mathrm{V} 5$ tags on these recombinant proteins (Fig. 5). Since the mammalian CSF1 interacts with the D2 and D3 domains of its cognate CSF1R (Chen et al., 2008), we engineered the (rXI)CSF1R to comprise of the D2 and D3 extracellular domains of the $X$. laevis receptor. Western blot analysis of the crosslinked $25 \mathrm{kDa}$ rXICSF1 ligand revealed a band shift to $50 \mathrm{kDa}$; indicative of $\mathrm{r} X I C S F 1$ dimerization (Fig. 5). Following DSS crosslinking, $r X / C S F 1 R$ could no longer be detected by western blot, which is typical of non-interacting proteins (Fig. 5). Notably, when the $r$ XICSF1 and $r$ XICSF1R were coincubated and crosslinked with DSS, a band shift to $130 \mathrm{kDa}$ was observed, indicating that the dimerized $\mathrm{r}$ XICSF1 interacted with two $40 \mathrm{kDa}$ molecules of $r X I C S F 1 R$ in solution (Fig. 5). The crosslinking of $r X I C S F 1 R$ in the presence of bovine serum albumin (BSA) did not yield a banding pattern, indicating lack of non-specific interactions (Fig. 5).

\section{rXICSF1R abrogates the rXICSF1-mediated recruitment and differentiation of tadpole peritoneal macrophages}

To confirm the biological roles of $r X I C S F 1$ and $r X I C S F 1 R$, we examined the ability of the recombinant ligand to elicit and differentiate tadpole peritoneal macrophages, and the capacity of the CSF1R D2-D3 extracellular domain-containing $r$ XICSF1R to abrogate this process by antagonizing the effects induced by $r X I C S F 1$ (Fig. 6). Twenty-four hoursfollowing intraperitoneal injection of tadpoles with the $X I C S F 1$ resulted in significant accumulation of peritoneal macrophages (Fig. 6A). In contrast, administration of $\mathrm{r} X I C S F 1 \mathrm{R}$ induced a reduction in the numbers of tadpole resident peritoneal phagocyte populations (Fig. 6A). Furthermore, a four-

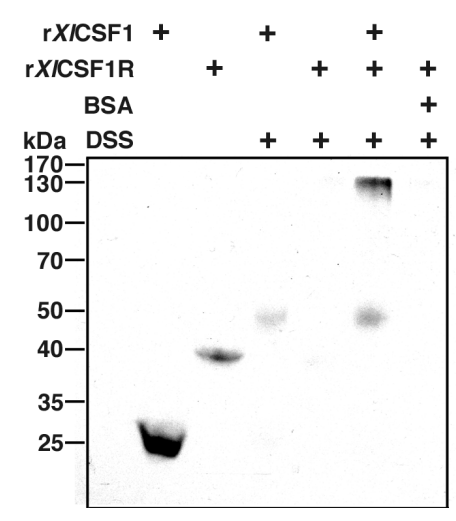

Fig. 5. In vitro $\mathrm{r} X I C S F 1$ and $\mathrm{r} X I C S F 1 R$ cross-linking studies. One microgram each of $r$ XICSF1, rXICSF1R, $r$ XICSF1 + rXICSF1R and BSA + rXICSF1R were incubated in APBS (100 $\mathrm{u}$ / final volume) for $30 \mathrm{~min}$ and cross-linked for 30 min using 2.5 mM DSS, final concentration. Cross-linking reactions were terminated by addition of $50 \mathrm{mM}$ Tris (final concentration). Reactions were resolved and visualized using SDS-PAGE and western blot against the V5 epitopes on the recombinant proteins. 
A

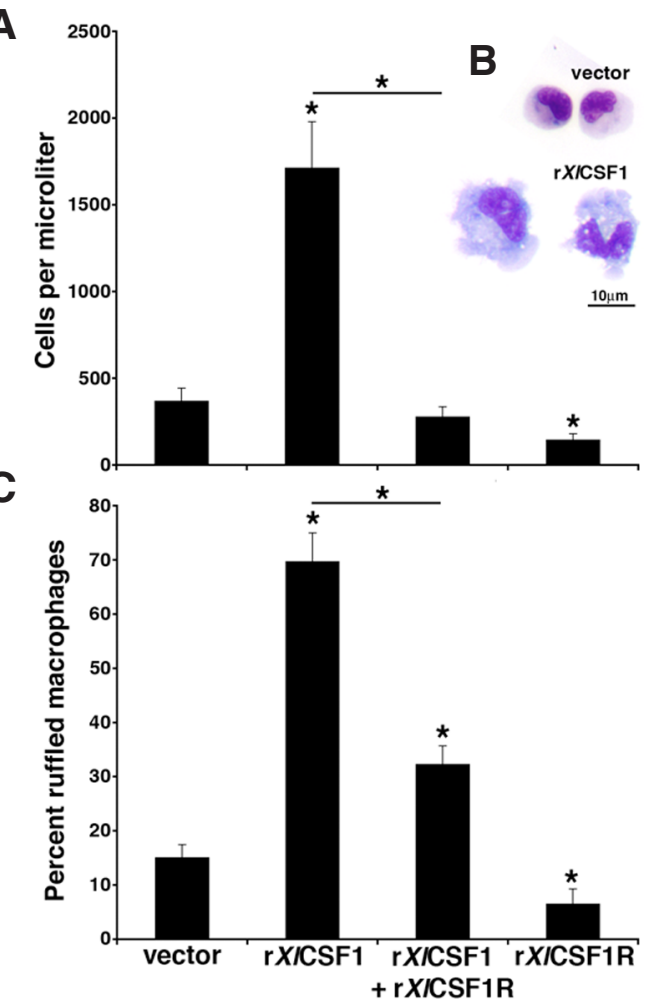

Fig. 6. The $r X I C S F 1 R$ abrogates the $r X I C S F 1-m e d i a t e d$ tadpole macrophage recruitment and differentiation. (A) Tadpoles were injected with vector control, 250ng of $r$ XICSF1, 1000ng of $r$ XICSF1R or a combination of rXICSF1 (250ng) and rXICSF1R (10000ng). After 24hrs peritoneal phagocytes were lavaged and enumerated. Results are means \pm SEM, $\mathrm{N}=6$ and the $\left({ }^{*}\right)$ above lines denotes significant difference between treatment groups indicated by the lines, $P<0.05$. (B) Morphological analysis of Giemsa-stained vector-control and rXICSF1R derived cultures. Scale bar $=10 \mu \mathrm{m}$. (C) Cultures from (A) were Giemsa-stained, enumerated for the presence of morphologically differentiated macrophages as exemplified in (B) by the rXICSF1R-derived cells. Results are expressed as percent means \pm SEM from ten random fields of view. The $\left(^{*}\right)$ above lines denotes significant difference between treatment groups indicated by the lines, $P<0.05$.

fold excess of $r X I C S F 1 R$ co-injected with $r X I C S F 1$ abrogated the rXICSF1-mediated macrophage elicitation (Fig. 6A).

Microscopy analysis of cytospin preparations stained by Giemsa revealed that peritoneal leukocytes obtained from tadpoles injected with vector control were comprised primarily of smaller mononuclear phagocytes, whereas $\mathrm{rXICSF} 1$ treatment resulted in the accumulation/differentiation of considerably larger, ruffled and highly vacuolated macrophages (Fig. 6B). On average, cells from vector control administered animals consisted of only $14.9 \%$ large, ruffled and vacuolated macrophages, whereas these larger cells comprised $69.6 \%$ of the $r$ XICSF1-elicited tadpole peritoneal phagocytes (Fig. $6 \mathrm{C}$ ). Notably, peritoneal phagocytes derived from animals that had been co-injected with $r X I C S F 1$ and $r X I C S F 1 R$ had significantly lower proportions (32.1\%) of these morphologically distinct macrophage populations as compared to the rXICSF1cultures (Fig. 6C). Interestingly, peritoneal phagocytes isolated from tadpoles administered $r$ XICSF1 R alone had significantly lower numbers of large, ruffled macrophages $(6.4 \%)$ than even those seen in the vector control cultures (Fig. 6C), suggesting that resi- dent peritoneal macrophages also rely on native CSF1 for survival.

Given that the administration of $r$ XICSF1R significantly affected the differentiation and abundance of resident tadpole peritoneal macrophages (see Fig. 6), we next assessed how rXICSF1R treatment would impact the tadpoles' capacity to recruit leukocytes into the peritoneum following heat-killed E. coli or FV3 challenge (Fig. 7A). Notably, the numbers of peritoneal leukocytes elicited one day after stimulation with heat-killed $E$. coli were dramatically decreased by co-injection with $r X I C S F 1 R$ (Fig. 7A). Similarly, macrophage infiltration induced one day after FV3 infection was significantly decreased by co-injecting $r X I C S F 1 R$ with the FV3 (Fig. $7 \mathrm{~A})$. These findings suggest that the macrophage-suppressive effects conferred by $r$ XICSF1R administration (Fig. 6) culminate in decreased capacities of resident mononuclear phagocytes to recruit additional leukocyte populations in response to immune stimuli.

Since we have shown that $X$. laevis macrophages derived by the recombinant ligand $r X I C S F 1$ increases tadpoles susceptibility to FV3 (Grayfer and Robert, 2014) and that converging evidence
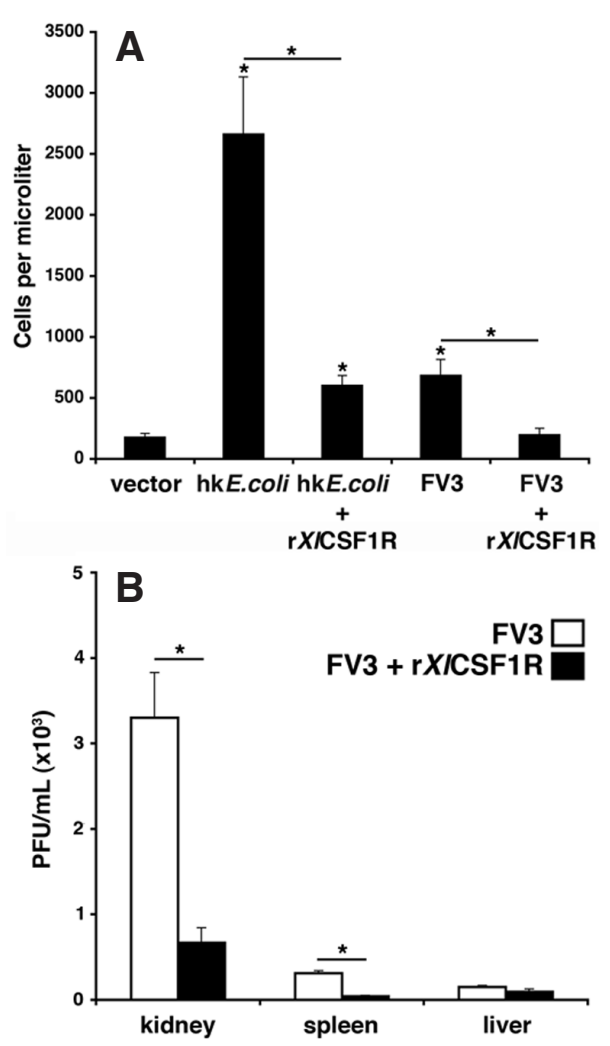

Fig. 7. The rXICSF1R abrogates heat-killed E. coli and Frog Virus 3 elicited recruitment of tadpole peritoneal leukocytes and reduces FV3 dissemination. (A) Tadpoles were injected with vector control, heat-killed (hk) E. coli, FV3 (104 PFU), a combination of hk E. coli and rXICSF1 (1 $\mu \mathrm{g})$ or a combination of FV3 $\left(10^{4} \mathrm{PFU}\right)$ and $r \mathrm{XICSF1R}(1 \mu \mathrm{g})$. After $24 \mathrm{hrs}$ peritoneal phagocytes were lavaged and enumerated. Results are means $\pm S E M, N=4$. $\left(^{*}\right)$ denotes statistical difference from the vector control and the $\left(^{*}\right)$ above lines denotes significant difference between treatment groups indicated by the lines, $P<0.05$. (B) Tadpoles were injected with $1 \times 10^{4}$ PFU of FV3 alone, or in combination with $1 \mu \mathrm{g}$ of $r$ XICSF1R. Following $24 \mathrm{hrs}$, tadpoles were sacrificed; their tissues were isolated and examined for infectious FV3 burdens by plaque assays. Results are means $\pm S E M, N=3$. (*) above lines denotes significant difference between treatment groups indicated by the lines, $P<0.05$. 
indicates that ranaviruses rely on macrophages to disseminate inside their hosts (reviewed in Grayfer et al., 2012), we postulated that ablation of tadpole resident peritoneal macrophages by $\mathrm{r} X I \mathrm{CSF} 1 \mathrm{R}$ should also reduce FV3 dissemination into tadpole organs. Accordingly, tadpoles were injected with FV3 alone, or in combination with $r$ XICSF1R and virus loads in various tissues were assessed the following day (Fig. 7B). In support of our previous findings, the $\mathrm{rXICSF1R}$ administration significantly reduced FV3 loads in kidney and spleen, but not liver (Fig. 7B). This suggests that peritoneal CSF1-dependent phagocytes are critical for the dissemination of this virus.

\section{Discussion}

This manuscript represents the first characterization of an amphibian CSF1R. Despite the poor conservation of the overall amino acid sequence among vertebrate CSF1R molecules, all CSFR1 gene products, including the $X$. laevis, share hallmark features including 5 putative immunoglobulin domains, structurally conserved cysteine residues as well as a disrupted tyrosine kinase domain. The extracellular portions of CSF1R molecules exhibit more divergence, possibly reflecting evolutionary drift to facilitate the binding of respective cognate CSF1 ligands, which also display low amino acid sequence conservation (Grayfer and Robert, 2013). By contrast, the intracellular catalytic tyrosine kinase domains of these respective CSF1R proteins are remarkably well conserved, perhaps marking the evolutionary functional necessity for retaining these protein sequences. The evolutionarily diverged CSF1R amino acid sequences of distinct vertebrate classes are also reflected in their phylogenetic relationships, wherein the fish, amphibian, avian, reptilian and mammalian receptors all branched in respective separate clades. Indeed the CSF1R catalytic domains have been evolutionarily conserved across vertebrates, suggesting conservation in downstream CSF1R cell signaling and presumably the resulting biological outcomes. However, many other aspects of lower vertebrate macrophage biology appear to be distinct from what has been documented in mammals. This includes varying teleost CSF1 ligand and receptor gene copy numbers (Hanington et al., 2007; Wang et al., 2008; Wang et al., 2014; Williams et al., 2002) and unique physiological localization of amphibian monopoiesis (Grayfer and Robert, 2013). It remains to be determined whether these differences arise from and/or are dependent on CSF1CSF1R functions which are different to those of mammals. Thus, it is possible that the monopoietic roles conferred by CSF1-CSF1R of distinct lower vertebrate species are at least partially unique to those described in mammals.

Whereas birds and mammals possess a single CSF1 gene expressing alternatively spliced transcripts, fish possess at least two distinct CSF1 genes that do not appear to produce alternatively spliced products (Hanington et al., 2007; Wang et al., 2008; Wang et al., 2014). Presently, it is unknown whether the functions of the different fish CSF1 genes correspond to those mediated by the respective alternatively spliced mammalian transcript products. Furthermore, at least some fish species, including Fugu, possess 2 distinct CSF1R genes (Williams et al., 2002). Therefore, it is quite possible that similar to the fish type II IFN system (Aggad et al., 2012; Grayfer and Belosevic, 2009; Grayfer et al., 2010; Shibasaki et al., 2013; Yabu et al., 2011), the multiple teleost CSF1 receptor and ligand gene products may exhibit complex interactions, distinct from the single ligand, single receptor strategy of higher vertebrates. In our recent study of the $X$. tropicalis and $X$. laevis CSF1 genes (Grayfer and Robert, 2013), we did not identify additional CSF1 gene copies in $X$. laevis and $X$. tropicalis genomes, nor did we detect additional CSF1R genes during the studies described here. It is noteworthy that despite our best efforts, using both conventional and RACE PCR approaches, we were unable to identify alternatively spliced $X$. laevis CSF1 transcripts (data not shown). Although more investigation are needed, it appears that alternatively spliced CSF1 and/or CSF1R genes are absent or at least of minor importance in Xenopus. It is possibly that the unique Xenopus monopoietic strategy requires a single non-alternatively spliced Xenopus CSF1 and a single CSF1R.

The highest level of CSF1R gene expression was observed in the lung and liver of $X$. laevis adults. Presumably these expression patterns reflect the presence of alveolar macrophages (Lin et al., 1989) and Kupffer cells (Amemiya et al., 2011), wherein the mammalian counterparts of both of these macrophage-lineage populations express high CSF1R levels. Notably, CSF1R gene expression increased with $X$. laevis development in the majority of tissues examined, including kidney, spleen, liver, lung and skin. This may represent the accumulation of resident macrophages, reflecting complex growing biological necessities for these cells with frog development and maturation. Alternatively, it is possible that the level of CSF-1R gene expression per cell increases during development. In addition, the CSF1Rgene expression increased in the muscle tissue of regressing tails from metamorphosing animal. Indeed, macrophages have been previously demonstrated to play crucial roles in tail and body muscle remodeling during metamorphosis (Nishikawa et al., 1998), where our present observations corroborate with these earlier findings. It will be interesting to examine the differences in CSF1 responsiveness of macrophage precursors in tadpoles and adult $X$. laevis, since they are both CSF1-responsive (Grayfer and Robert, 2013; Grayfer and Robert, 2014), whereas macrophage development in adult involves the bone marrow that is absent in tadpoles (Grayfer and Robert, 2013).

Following FV3 infection, both tadpoles and adults exhibited increased kidney CSF1R gene expression, which is interesting considering that the kidney is the primary site of FV3 replication (Gantress etal., 2003; Robert et al., 2007). In addition, macrophages are intimately involved in both immunity and the infection strategy of FV3 (Morales et al., 2010; Grayfer et al., 2012). Therefore, it seems reasonable to speculate that CSFRgene expression increases due to the infiltration of kidney tissues by macrophage-lineage cells. Intriguingly, the spleen and liver CSF1R gene expression patterns induced by FV3 infection were markedly different between tadpoles and adults, possibly underlining their distinct monopoietic strategies. In light of our recent findings that the $X$. laevis bone marrow serves as the prime source of macrophage precursors (Grayfer and Robert, 2013), together with our present observation that FV3 and heat-killed $E$. coli both elicit increased bone marrow CSF1R expression may indicate that in response to immunological challenges, adult Xenopus increase monopoietic activity at the level of the bone marrow. By contrast, tadpoles do not possess bone marrow and thus, presumably orchestrate monopoiesis in the hematopoietic liver. This would explain the increased CSF1R gene expression in FV3-infected tadpole, but not adult liver tissues. In comparison to adults, the tadpole spleen may likewise be more prominently involved in macrophage development and immunity as 
reflected in substantially more upregulated CSF1R gene expression within this tadpole tissue following FV3 challenge. It is interesting that heat-killed E. coli did not elicit significant CSF1R expression changes in any of the tadpole tissues examined, whereas following this inflammatory stimulus adults exhibited substantially more robust CSF1R gene expression increases in the spleen, liver and bone marrow than observed following FV3 infection. These disparities may reflect differences in pathogen pattern recognition receptor expression between tadpoles and adults, and a physiological necessity for more prominent adult monopoietic responses to inflammatory, rather than viral challenges. A greater understanding of Xenopus macrophage development and immune responses will no doubt shed light on this present enigma. We emphasize that in our present work $E$. coli was used as an inflammatory stimulus rather than a direct point of comparison with the more relevant FV3 viral challenge. Future $X$. laevis infection studies using relevant bacterial pathogens will lend to our understanding of the differences in macrophage involvement during different host responses.

The mammalian dimeric CSF1 binds exclusively to the D2 and D3 domains of the CSF1R, dimerizing the receptor (Chen et al., 2008). Our in vitro binding studies indicate that the D2 and D3 domains of a recombinant amphibian CSF1R are also sufficient to bind the recombinant homodimerized CSF1 ligand. More detailed studies will be needed to elucidate the modalities and stoichiometry of these interactions. Notably, the $X I C S F 1 R$ very effectively inhibited rXICSF1-mediated tadpole elicitation and development of macrophages into cells morphologically resembling mature, differentiated populations. Furthermore, rXICSF1R administration also ablated the recruitment of peritoneal leukocytes elicited by heat-killed $E$. coli and the FV3. Since tadpoles administered with $r$ XICSF1R exhibited diminishing numbers of mature resident peritoneal macrophages, the compromised capacities of rXICSF1R-treated tadpoles to recruit leukocytes into the peritoneum upon ip immune challenges likely reflects a functional impairment of peritoneal macrophages, which would normally chemo-attract additional immune populations in response to immune stimuli. Notably, teleost fish appear to have evolved an additional regulatory mechanism of monopoiesis and inflammation whereby they produce an alternatively spliced, soluble CSF1R (Barreda et al., 2005; Rieger et al., 2014a; Rieger et al., 2014b). Intriguingly, this moiety only possesses the D1 and D2 domains of the membrane-bound CSF1 R and yet this molecule is highly biologically active and inhibits fish macrophage proliferation and inflammatory responses (Barreda et al., 2005; Rieger et al., 2014a; Rieger et al., 2014b). It will be interesting to learn which specific domains are involved in the interactions of the respective teleost CSF1 ligand(s), soluble and membrane bound CSF1Rs and whether a similar system is present in amphibian species.

Converging evidence indicate that macrophage-lineage cells are utilized by ranaviruses as a means of dissemination within their hosts (Grayfer et al., 2012). In addition, CSF1-derived macrophages render tadpoles more susceptible to FV3 (Grayfer and Robert, 2014). Here, we show that intraperitoneal administration of rXICSF1R reduces resident phagocyte numbers and impairs some of their functions such as leukocyte recruitment. The treatment with rXICSF1R also results in decreased dissemination of FV3 from the inoculation site of the peritoneum to the kidney (central site of ranavirus replication) and the spleen (central immune organ), whereas it does not affect low viral dissemination into the liver. These observations underline the complexity of the roles of mononuclear phagocytes as both mediators of anti-RV immune responses and culprits in the progression of these infections.

The CSF1-CSF1R axis represents the focal point of vertebrate monopoiesis and it has become apparent that evolutionarily more ancestral species such as teleosts and amphibians may possess varying strategies for CSF1-mediated macrophages development, distinct from those described in mammalian species. Further research into CSF1 and CSF1R macrophage biology of lower vertebrates will yield new insights into the evolutionary basis of monopoiesis and permit the development of more effective preventative measures against pathogens that infiltrate macrophagelineage cells of more ancient species.

\section{Materials and Methods}

\section{Animals}

Outbred pre-metamorphic (stage 54, (Thors et al., 1982a; Thors et al., 1982b)) tadpoles, metamorphic (stage 64) and adult (2 years old) frogs were obtained from our $X$. laevis research resource for immunology at the University of Rochester (http://www.urmc.rochester.edu/mbi/resources/ Xenopus-laevis/). All animals were handled under strict laboratory and University Committee on Animal Research regulations (Approval number 100577/2003-151).

\section{Identification and analysis of $X$. laevis colony-stimulating factor-1 receptor}

The identification of the $X$. laevis CSF1 was described previously (Grayfer and Robert, 2013). A fragment of the $X$. laevis CSF1R cDNA transcript was identified using primers against the predicted $X$. tropicalis CSF1R sequence (Acc. no.: BC082504). Subsequently, RACE PCR was performed in accordance with manufacturers' directions (Clonetech) to identify the complete $X$. laevis CSF1R cDNA transcript (Acc. No.: KM400585). All primer sequences are available upon request.

Protein sequence alignments were performed using the Clustal W software (http://www.ebi.ac.uk/clustalw/). Signal peptide regions were identified using the SignalP 3.0 Server (http://www.cbs.dtu.dk/services/ SignalP/). Protein motif and domain predictions were achieved using the ELM (http://elm.eu.org/) and SMART (http://smart.embl-heidelberg.de/) servers. Phylogenetic analysis was performed by Clustal $X$ software using the neighbor joining method and bootstrapped 10,000 times, with values expressed as percentages.

\section{Production of rXICSF1 and rXICSF1R}

The production of the $\mathrm{rXICSF} 1$ has been described previously (Grayfer and Robert, 2013). The $r X I C S F 1 R$ was produced by transfecting Sf9 insect cells (cellfectin II, Invitrogen) with the pMIB/V5 HisAinsect expression vector (Invitrogen) containing the $X$. laevis CSF1R sequence corresponding to the IG2 and IG3 domains of the extracellular portion of the protein. Transfected Sf9 supernatants were confirmed for $r$ XICSF1R expression, positive transfectants were scaled up to $500 \mathrm{~mL}$ in liquid cultures and grown for 6 days in blasticidin $(10 \mu \mathrm{g} / \mathrm{mL})$-containing medium. Resulting supernatants were dialyzed overnight at $4 / \mathrm{C}$ against $150 \mathrm{mM}$ sodium phosphate, concentrated against polyethylene glycol flakes $(8 \mathrm{kDa})$, dialyzed overnight at 4CC against $150 \mathrm{mM}$ sodium phosphate and passed through Ni-NTA agarose columns (Qiagen). Columns were washed with $2 \times 10$ volumes of high stringency wash buffer $(0.5 \%$ Tween $20 ; 50 \mathrm{mM}$ Sodium Phosphate; $500 \mathrm{mM}$ Sodium Chloride; $100 \mathrm{mM}$ Imidazole) and $5 \mathrm{x}$ with low stringency wash buffer (as above, but with $40 \mathrm{mM}$ Imidazole). The rXICSF1R was eluted in fractions using $400 \mathrm{mM}$ Imidazole. The purity of the eluted fractions was confirmed by silver-stain and the presence of $r$ XICSF1R was assessed by western blot against the V5 epitope on the recombinant protein. Fractions containing the $r X I C S F 1 R$ were pooled and the protein concentration determined by the Bradford Protein Assay (BioRad). A protease inhibitor cocktail (Roche) was added to the purified protein, which was then aliquoted 
and stored at $-20^{\circ} \mathrm{C}$ until use.

The vector control was produced by transfecting Sf9 cells with an empty expression vector and treating the resulting supernatants akin to and in parallel to the $\mathrm{rXICSF} 1$ production.

\section{Cell culture media}

The amphibian (ASF) culture medium used in these studies has been previously described (Robert et al., 2007). All cell cultures were established using ASF supplemented with $10 \%$ fetal bovine serum, $2.5 \%$ heat-inactivated $X$. laevis serum, $20 \mu \mathrm{g} / \mathrm{mL}$ kanamycin and $100 \mathrm{U} / \mathrm{mL}$ penicillin / $100 \mu \mathrm{g} /$ $\mathrm{mL}$ streptomycin (Gibco). Amphibian PBS (APBS) has been previously described (Robert et al., 2007).

\section{Isolation of rXICSF1-elicited tadpole macrophages}

Tadpoles at developmental stages 54 (Stg. 54; (Thors et al., 1982a; Thors et al., 1982b)) were intraperitoneally (ip) injected with $10 \mu \mathrm{L}$ of the vector control, rXICSF1 (250 ng), rXICSF1R (1000 ng) or a combination of $r$ XICSF1 (250 ng) and rXICSF1R (1000 ng) in $10 \mu \mathrm{L}$ volumes. After 24 hrs, peritoneal macrophages were collected by lavage with $50 \mu \mathrm{L}$ volumes of APBS. Cells were enumerated using trypan blue exclusion, collected on glass slides by cytospin and stained with Giemsa (Fluka).

\section{Frog Virus 3 stocks and animal infections}

Fathead minnow cells (FHM; American Type Culture Collection, ATCC No.: CCL-42) were maintained in DMEM (Invitrogen) supplemented with $10 \%$ fetal bovine serum (Invitrogen), penicillin $(100 \mathrm{U} / \mathrm{mL}$ ) and streptomycin $(100 \mu \mathrm{g} / \mathrm{mL})$ with $5 \% \mathrm{CO}_{2}$ at $30^{\circ} \mathrm{C}$. FV3 was grown by a single passage on $\mathrm{FMH}$ cells, purified by ultracentrifugation on a $30 \%$ sucrose cushion and quantified by plaque assay on BHK monolayer under an overlay of $1 \%$ methylcellulose (Morales et al., 2010).

Tadpoles and adult frogs were infected by ip injections with previouslyestablished (Gantress et al., 2003; Hanington et al., 2007; Robert et al., 2005) infection doses of $1 \times 10^{4}$ and $5 \times 10^{6}$ plaque forming units (PFU) of FV3, respectively. Three and six days post infection (dpi) animals were euthanized by immersion in $0.5 \%$ tricaine methane sulfonate (MS-222), tissues removed and processed for RNA isolation.

For determination of FV3 loads, tadpoles were ip injected with $1 \times 10^{4}$ PFU of FV3 alone, or in combination with $1 \mu \mathrm{g}$ of $r X I C S F 1 R$. After $24 \mathrm{hrs,}$ tadpoles were sacrificed, their tissues excised and processed for plaque forming assay analysis to determine respective infectious FV3 burdens.

\section{Heat-killed Escherichia coli stimulation}

E. coli (XL1-blue, Strategene, La Jolla, Ca.) cultured overnight at $37^{\circ} \mathrm{C}$, were boiled for 1 hour, pelleted by centrifugation and resuspended in one-tenth of the initial volume (approximately $1 \times 10^{8}$ bacteria/mL) of APBS. Tadpoles and adult frogs were injected ip with 10 and $100 \mu \mathrm{l}$ of this heat-killed (hk) bacterial preparation.

\section{Quantitative gene expression analysis}

Total RNA was extracted from frog tissues using the Trizol reagent following the manufacturer's directions (Invitrogen). All cDNA synthesis was performed using the iScript cDNA synthesis kit according to manufacturers' directions (Bio-Rad, Hercules, CA) using $500 \mathrm{ng}$ of total DNAse treated (Ambion) RNA.

Relative qRT-PCR gene expression analyses was performed via the delta^delta CT method using validated $X$. laevis CSF1R-specific primers, with expression examined relative to the GAPDH endogenous control and normalized against the lowest observed expression. All experiments were performed using the $\mathrm{ABI} 7300$ real-time $\mathrm{PCR}$ system and PerfeCTa ${ }^{\circledR}$ SYBR Green FastMix, ROX (Quanta). Expression analysis was performed using $\mathrm{ABI}$ sequence detection system software (SDS). All primers were validated prior to use. All primer sequences are available upon request.

\section{In vitro rXICSF1 and $r X I C S F 1 R$ cross-linking studies}

One microgram each of $r$ XICSF1, $r X I C S F 1 R, r X I C S F 1+r X I C S F 1 R$ and
$\mathrm{BSA}+\mathrm{r} X / \mathrm{CSF} 1 \mathrm{R}$ were incubated in APBS (100ul final volume) for $30 \mathrm{~min}$, cross-linked for 30 min using $2.5 \mathrm{mM}$ disuccinimidyl suberate (DSS, final concentration, Thermo Scientific). Cross-linking was terminated for $15 \mathrm{~min}$ by the addition of $50 \mathrm{mM}$ Tris (final concentration). The reactions were then resolved and visualized using SDS-PAGE and western blot against the V5 epitopes on the recombinant proteins and developed using ECL (Pierce) on X-ray film (Eastman Kodak Co.)

\section{Statistical analysis}

Statistical analysis was performed using a one-way analysis of variance (ANOVA) and Tukey's post hoc test, using Vassar Stat (http://faculty.vassar. edu/lowry//anova1u.html) statistical program. Probability level of $\mathrm{P}<0.05$ was considered significant.

\section{Acknowledgements}

This work was supported by National Institute of Health (R24-Al-059830) and National Science Foundation (IOB-074271) grants to J.R. L.G. was supported by a National Sciences and Engineering Research Council of Canada Postdoctoral Fellowship and a Life Sciences Research Fellowship from the Howard Hughes Medical Institute. We thank Tina Martin for animal husbandry. This manuscript was improved by the insightful suggestions of one anonymous reviewer.

\section{References}

AGGAD D, STEIN C, SIEGERD, MAZELM, BOUDINOTP, HERBOMELP, LEVRAUD J P, LUTFALLA G, LEPTIN M. (2012) In vivo analysis of Ifn-gamma1 and Ifngamma2 signaling in zebrafish. J Immunol 185: 6774-6782.

AMEMIYA H, KONO H, FUJII H. (2011) Liver regeneration is impaired in macrophage colony stimulating factor deficient mice after partial hepatectomy: the role of $\mathrm{M}$ CSF-induced macrophages. J Surg Res 165: 59-67.

BARREDA D R, HANINGTON P C, STAFFORD J L, BELOSEVIC M. (2005) A nove soluble form of the CSF-1 receptor inhibits proliferation of self-renewing macrophages of goldfish (Carassius auratus L.). Dev Comp Immunol 29: 879-894.

BELOSEVIC M, HANINGTON P C, BARREDA D R. (2006) Development of goldfish macrophages in vitro. Fish Shellfish Immunol 20: 152-171.

BOBER L A, GRACE M J, PUGLIESE-SIVO C, ROJAS-TRIANA A, SULLIVAN L M, NARULAS K. (1995) The effects of colony stimulating factors on human monocyte cell function. Int J Immunopharmacol 17: 385-392.

CHEN X, LIU H, FOCIA P J, SHIM A H, HE X. (2008) Structure of macrophage colony stimulating factor bound to FMS: diverse signaling assemblies of class III receptor tyrosine kinases. Proc Natl Acad Sci USA 105: 18267-18272.

CHINCHAR V G. (2002) Ranaviruses (family Iridoviridae): emerging cold-blooded killers. Arch Virol 147: 447-470.

CHINCHAR V G, HYATT A, MIYAZAKI T, WILLIAMS T. (2009) Family Iridoviridae: poor viral relations no longer. Curr Top Microbiol Immunol 328: 123-170.

DAI X M, RYAN G R, HAPEL A J, DOMINGUEZ M G, RUSSELL R G, KAPP S, SYLVESTRE V, STANLEY E R. (2002) Targeted disruption of the mouse colonystimulating factor 1 receptor gene results in osteopetrosis, mononuclear phagocyte deficiency, increased primitive progenitor cell frequencies, and reproductive defects. Blood 99: 111-120.

GANTRESS J, MANIERO G D, COHEN N, ROBERT J. (2003) Development and characterization of a model system to study amphibian immune responses to iridoviruses. Virology 311: 254-262.

GARCEAU V, SMITH J, PATON I R, DAVEY M, FARES M A, SESTER D P, BURT D W, HUME D A. (2010) Pivotal Advance: Avian colony-stimulating factor 1 (CSF-1), interleukin-34 (IL-34), and CSF-1 receptor genes and gene products. J Leukoc Biol 87: 753-764

GRAYFER L, ANDINO FDE J, CHEN G, CHINCHAR G V, ROBERT J. (2012) Immune evasion strategies of ranaviruses and innate immune responses to these emerging pathogens. Viruses 4: 1075-1092.

GRAYFER L, BELOSEVIC M. (2009) Molecular characterization of novel interferon gamma receptor 1 isoforms in zebrafish (Danio rerio) and goldfish (Carassius auratus L.). Mol Immunol 46: 3050-3059.

GRAYFER L, GARCIA E G, BELOSEVIC M. (2010) Comparison of macrophage 
antimicrobial responses induced by type II interferons of the goldfish (Carassius auratus L.). J Biol Chem 285: 23537-23547.

GRAYFER L, ROBERTJ. (2013) Colony-stimulating factor-1-responsive macrophage precursors reside in the amphibian (Xenopus laevis) bone marrow rather than the hematopoietic subcapsular liver. J Innate Immun 5: 531-542.

GRAYFER L, ROBERT J. (2014) Divergent antiviral roles of amphibian (Xenopus laevis) macrophages elicited by colony-stimulating factor-1 and interleukin-34. J Leukoc Biol doi:10.1189/jlb.4A0614-295R

GUILBERT LJ, STANLEYER. (1980) Specific interaction of murine colony-stimulating factor with mononuclear phagocytic cells. J Cell Biol 85: 153-159.

HADJI-AZIMI I, COOSEMANS V, CANICATTI C. (1987) Atlas of adult Xenopus laevis laevis hematology. Dev Comp Immunol 11: 807-874.

HADJI-AZIMI I, COOSEMANS V, CANICATTI C. (1990) B-lymphocyte populations in Xenopus laevis. Dev Comp Immunol 14: 69-84.

HANINGTON P C, WANG T, SECOMBES C J, BELOSEVIC M. (2007) Growth factors of lower vertebrates: characterization of goldfish (Carassius auratus L.) macrophage colony-stimulating factor-1. J Biol Chem 282: 31865-31872.

HONDA T, NISHIZAWA T, UENOBE M, KOHCHI C, KURODA A, OTOTAKE M, NAKANISHI T, YOKOMIZO Y, TAKAHASHI Y, INAGAWA H, SOMA G. (2005) Molecular cloning and expression analysis of a macrophage-colony stimulating factor receptor-like gene from rainbow trout, Oncorhynchus mykiss. Mol Immunol42: 1-8.

HOW G F, VENKATESHB, BRENNERS. (1996) Conserved linkage between the puffer fish (Fugu rubripes) and human genes for platelet-derived growth factor receptor and macrophage colony-stimulating factor receptor. Genome Res 6: 1185-1191.

KARBASSI A, BECKER J M, FOSTER J S, MOORE R N. (1987) Enhanced killing of Candida albicans by murine macrophages treated with macrophage colonystimulating factor: evidence for augmented expression of mannose receptors. $J$ Immunol 139: 417-421.

LANE M C, SHEETS M D. (2002) Primitive and definitive blood share a common origin in Xenopus: a comparison of lineage techniques used to construct fate maps. Dev Biol 248: 52-67.

LICHANSKA A M, BROWNE C M, HENKEL G W, MURPHY K M, OSTROWSKI M C, MCKERCHER S R, MAKI R A, HUME D A. (1999) Differentiation of the mononuclear phagocyte system during mouse embryogenesis: the role of transcription factor PU.1. Blood 94: 127-138.

LIN H S, LOKESHWAR B L, HSU S. (1989) Both granulocyte-macrophage CSF and macrophage CSF control the proliferation and survival of the same subset of alveolar macrophages. J Immunol 142: 515-519.

MORALES HD, ABRAMOWITZ L, GERTZJ, SOWAJ, VOGELA, ROBERT J. (2010) Innate immune responses and permissiveness to ranavirus infection of peritoneal leukocytes in the frog Xenopus laevis. J Virol 84: 4912-4922.

MUNN D H, CHEUNG N K. (1995) Antibody-independent phagocytosis of tumor cells by human monocyte-derived macrophages cultured in recombinant macrophage colony-stimulating factor. Cancer Immunol Immunother 41: 46-52.

NEUMANN N F, BARREDA D R, BELOSEVIC M. (2000) Generation and functional analysis of distinct macrophage sub-populations from goldfish (Carassius auratus L.) kidney leukocyte cultures. Fish Shellfish Immunol 10: 1-20.

NISHIKAWAA, MURATA E, AKITAM, KANEKO K, MORIYA O, TOMITAM, HAYASH $\mathrm{H}$. (1998) Roles of macrophages in programmed cell death and remodeling of tail and body muscle of Xenopus laevis during metamorphosis. Histochem Cell Biol 109: 11-17.

PARICHY D M, RANSOM D G, PAW B, ZON L I, JOHNSON S L. (2000) An orthologue of the kit-related gene fms is required for development of neural crest-derived xanthophores and a subpopulation of adult melanocytes in the zebrafish, Danio rerio. Development 127: 3031-3044.

PETTERSEN E F, INGERSLEV H C, STAVANG V, EGENBERG M, WERGELAND H I. (2008) A highly phagocytic cell line TO from Atlantic salmon is CD83 positive and M-CSFR negative, indicating a dendritic-like cell type. Fish Shellfish Immunol 25: 809-819.

PIXLEY F J, STANLEY E R. (2004) CSF-1 regulation of the wandering macrophage: complexity in action. Trends Cell Biol 14: 628-638.

RIEGER A M, HANINGTON P C, BELOSEVIC M, BARREDA D R. (2014a) Control of CSF-1 induced inflammation in teleost fish by a soluble form of the CSF-1 receptor. Fish Shellfish Immunol 41: 45-51.

RIEGER A M, KONOWALCHUK J D, HAVIXBECK J J, ROBBINS J S, SMITH M K, LUND J M, BARREDADR. (2014b) A soluble form of the CSF-1 receptor contributes to the inhibition of inflammation in a teleost fish. Dev Comp Immuno/39: 438-446.

ROBERT J, ABRAMOWITZL, GANTRESS J, MORALES HD. (2007) Xenopus laevis: a possible vector of Ranavirus infection? J Wildl Dis 43: 645-652.

ROBERT J, MORALES H, BUCK W, COHEN N, MARR S, GANTRESS J. (2005) Adaptive immunity and histopathology in frog virus 3-infected Xenopus. Virology 332: 667-675

SHIBASAKI Y, YABU T, ARAKI K, MANO N, SHIBA H, MORITOMO T, NAKANISHIT. (2013) Peculiar monomeric interferon gammas, IFNgammarel 1 and IFNgammare 2, in ginbuna crucian carp. FEBS J 281: 1046-56.

STANLEY E R, BERG K L, EINSTEIN D B, LEE P S, PIXLEY F J, WANG Y, YEUNG $Y$ G. (1997) Biology and action of colony--stimulating factor-1. Mol Reprod Dev 46: 4-10.

SWEET M J, HUME D A. (2003) CSF-1 as a regulator of macrophage activation and immune responses. Arch Immunol Ther Exp (Warsz) 51: 169-177.

THORS F, DE KORT E J, NIEUWENHUYS R. (1982a) On the development of the spinal cord of the clawed frog, Xenopus laevis. I. Morphogenesis and histogenesis. Anat Embryol (Berl) 164: 427-441.

THORS F, DE KORT E J, NIEUWENHUYS R. (1982b) On the development of the spinal cord of the clawed frog, Xenopus laevis. II. Experimental analysis of differentiation and migration. Anat Embryol (Berl) 164: 443-454.

TUSHINSKI R J, OLIVER I T, GUILBERT L J, TYNAN P W, WARNER J R, STANLEY E R. (1982) Survival of mononuclear phagocytes depends on a lineage-specific growth factor that the differentiated cells selectively destroy. Cell 28: 71-81.

WANG T, HANINGTON P C, BELOSEVIC M, SECOMBES C J. (2008) Two macrophage colony-stimulating factor genes exist in fish that differ in gene organization and are differentially expressed. J Immunol 181: 3310-3322.

WANG T, KONO T, MONTE M M, KUSE H, COSTA M M, KORENAGA H, MAEHR T, HUSAIN M, SAKAI M, SECOMBES C J. (2014) Identification of IL-34 in teleost fish: differential expression of rainbow trout IL-34, MCSF1 and MCSF2, ligands of the MCSF receptor. Mol Immunol 53: 398-409.

WILLIAMS H, BRENNER S, VENKATESH B. (2002) Identification and analysis of additional copies of the platelet-derived growth factor receptor and colony stimulating factor 1 receptor genes in fugu. Gene 295: 255-264.

WILLIAMST, BARBOSA-SOLOMIEU V, CHINCHAR V G. (2005)Adecade of advances in iridovirus research. Adv Virus Res 65: 173-248.

YABU T, TODA H, SHIBASAKI Y, ARAKI K, YAMASHITA M, ANZAI H, MANO N, MASUHIRO Y, HANAZAWA S, SHIBA H, MORITOMO T, NAKANISHI T. (2011) Antiviral protection mechanisms mediated by ginbuna crucian carp interferon gamma isoforms 1 and 2 through two distinct interferon gamma-receptors. $J$ Biochem 150: 635-648. 


\section{Further Related Reading, published previously in the Int. J. Dev. Biol.}

Sexual dimorphism of AMH, DMRT1 and RSPO1 localization in the developing gonads of six anuran species

Rafal P. Piprek, Anna Pecio, Katarzyna Laskowska-Kaszub,Jacek Z. Kubiak and Jacek M. Szymura

Int. J. Dev. Biol. (2013) 57: 891-895

Dual embryonic origin of the hyobranchial apparatus in the Mexican axolotl (Ambystoma mexicanum)

Asya Davidian and Yegor Malashichev

Int. J. Dev. Biol. (2013) 57: 821-828

Clonal analyses in the anterior pre-placodal region: implications for the early lineage bias of placodal progenitors

Sujata Bhattacharyya and Marianne E. Bronner

Int. J. Dev. Biol. (2013) 57: 753-757

Amphibian interorder nuclear transfer embryos reveal conserved embryonic gene transcription, but deficient DNA replication or chromosome segregation

Patrick Narbonne and John B. Gurdon

Int. J. Dev. Biol. (2012) 56: 975-986

Origins of Cdx1 regulatory elements suggest roles in vertebrate evolution

Stephen J. Gaunt and Yu-Lee Paul

Int. J. Dev. Biol. (2011) 55: 93-98

Reptile scale paradigm: Evo-Devo, pattern formation and regeneration

Cheng Chang, Ping Wu, Ruth E. Baker, Philip K. Maini, Lorenzo Alibardi and Cheng-Ming Chuong

Int. J. Dev. Biol. (2009) 53: 813-826

Proteomics analysis of regenerating amphibian limbs: changes during the onset of regeneration

Michael W. King, Anton W. Neff and Anthony L. Mescher

Int. J. Dev. Biol. (2009) 53: 955-969
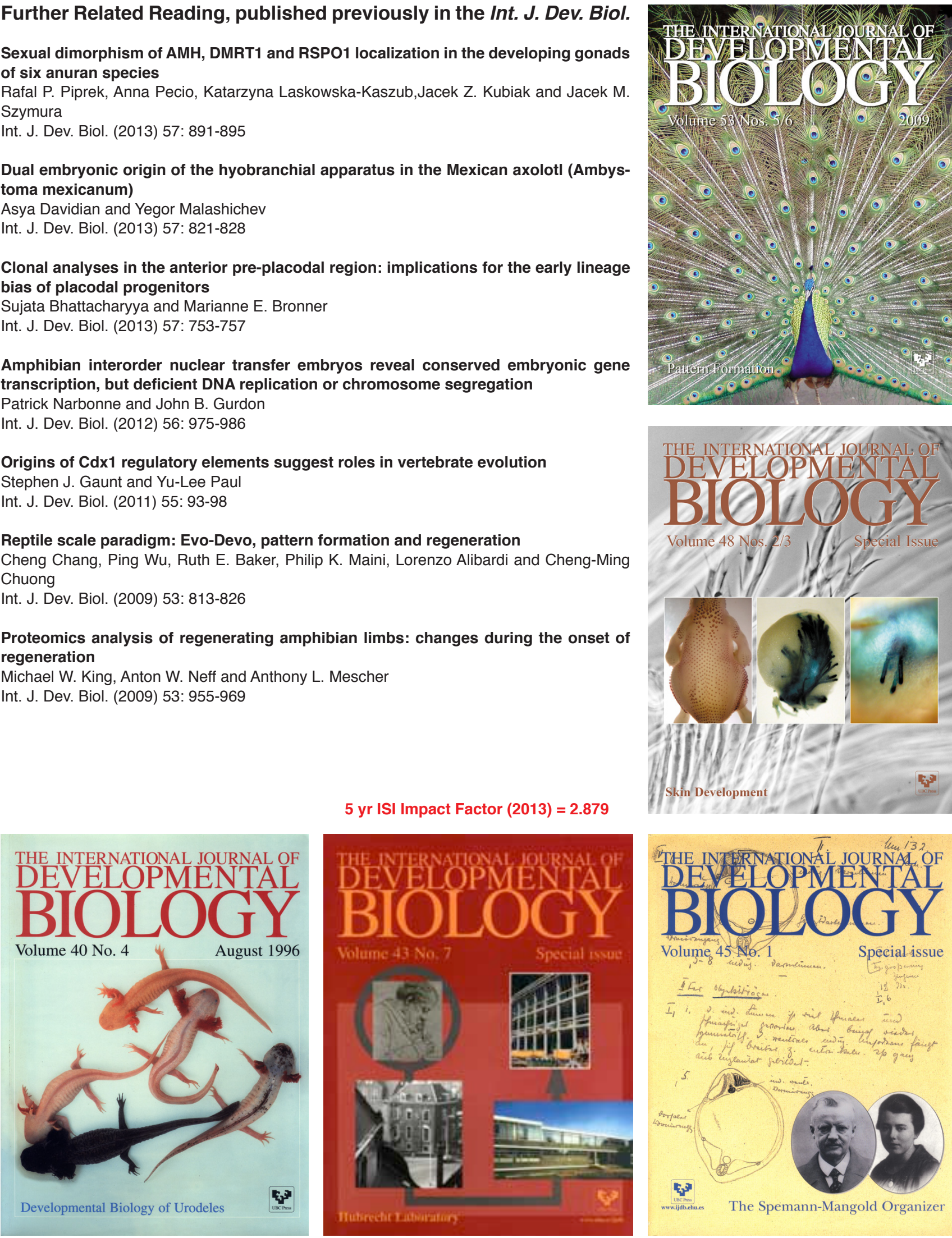

Volume 45 No. 1

Special-issue

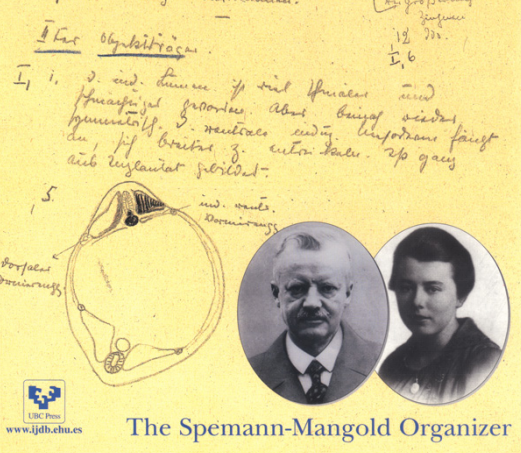

